\title{
Experiences of undergraduate nursing students of standardized patient methodology in their transition to nursing practice in Ontario Canada
}

\author{
Eva Hava Peisachovich, Raya Gal, Samantha Johnson \\ School of Nursing, York University, Toronto, Canada
}

Received: June 23, 2016

DOI: $10.5430 /$ jnep.v7n3p1

\author{
Accepted: September 28, $2016 \quad$ Online Published: October 17, 2016 \\ URL: http://dx.doi.org/10.5430/jnep.v7n3p1
}

\begin{abstract}
This study was conducted to explore and understand undergraduate nursing students' experiences with standardized-patient methodology during their final year of study and to identify the value of this form of teaching-learning approach in transition to practice milieus. The study, which employed qualitative-case-study research design, followed three undergraduate students who were individually videotaped interacting with two standardized patients during two clinical scenarios. The videotaping was followed by stimulated recall of the two interactions. Finally, participants were interviewed individually about their experiences with this form of methodology. A thematic analysis was conducted to derive themes and subthemes from contents of the videotapes, individual stimulated-recall sessions, and individual interviews. Four themes and nine subthemes emerged through thematic analysis. These results endorse the utility of standardized patient methodology; further, they offer suggestions for enhancing and expanding its use. This exploration of student responses to standardized-patient methodology enhances integration of complex realities, thus creating a bridge between theory and practice and magnifying the benefits of this approach.
\end{abstract}

Key Words: Simulation, Standardized patient methodology, Nursing, Education

\section{INTRODUCTION}

An overwhelming $70 \%$ of unforeseen workplace events involve miscommunication as a root cause. ${ }^{[1]}$ In organizations and industries with a relatively high degree of risk, and particularly in health-care milieus, effective communication and interpersonal skills have been shown to achieve positive patient outcomes with fewer errors.

Simulation and experiential-learning approaches, which have been shown to enhance application and transfer of knowledge and skills, have therefore been gaining popularity in higher education settings, primarily in the health-care disciplines. ${ }^{[2-5]}$ The application of simulation supports the synthesis of knowledge and the development of insight, profes- sional competence, communication skills, and confidence in practice, as it provides students an opportunity to develop competency in difficult interpersonal situations. ${ }^{[6-8]}$

One simulation-based learning approach that is widely cited in scholarly literature is the use of the standardized patient $(\mathrm{SP})^{[9,10]}$ — a person specially trained in simulation methodology to portray a specific clinical encounter. SPs are actors trained to realistically reproduce clinical scenarios by providing specific information, displaying signs and symptoms, and creating a realistic clinical picture of a patient-learner encounter in a consistent or standardized manner. ${ }^{[11]}$ Thus, they provide faculty and students opportunities to teach, practice, assess, and refine clinical skills, including communication,

*Correspondence: Eva Hava Peisachovich; Email: peva@yorku.ca; Address: School of Nursing, York University, Toronto, Canada. 
interview, diagnostic, and psychomotor skills.

The use of SP methodology has been shown to contribute to the systematic development of experiential education (EE); it offers novice health-care providers an opportunity to learn in a safe, risk-free environment and affords faculty the flexibility to provide students with realistic clinical situations. These scenarios often do not match the textbook portrayal and are, more specifically, the kind of experiences that students may not be exposed to in their clinical rotation. ${ }^{[12-15]}$

Given that the nature of nurses' work takes place in diverse and complex care settings, the use and application of SP methodology is an invaluable tool in the transition to practice. Although SPs have been used in many disciplines to engage students in experiential learning, it is a new methodology in nursing education; ${ }^{[10]}$ as a result, there is limited research available associated with SP methodology in this arena. The aim of this study is to expand the body of research by observing undergraduate nursing students' experiences with this form of simulation and exploring how it can best be applied within a teaching-learning milieu. Gaining both evidence and understanding of how this form of pedagogical methodology benefits nurse educators and students is a motivating factor of the study.

In this study, the use of SP methodology functions as a learning tool by providing participants with a realistic clinical environment in which to interact with, and explore the character and personality of the SP. These interactions allow participants to be actively involved in self-assessment and to obtain sustainable, formative feedback. Findings of the study facilitate an understanding of critical emotional competencies including communication and interpersonal skills, conflict and leadership skills, and interviewing skills, which are all linked to effective performance in nursing education and practice.

\section{Methods}

This study is guided by a central research question: What are undergraduate nursing students' experiences of SP methodology as a form of experiential education in their transition to practice? Understanding the answers to this question is fundamental both to the nursing profession and to the successful education of future nurses - particularly in the area of developing communication and interpersonal skills, which are key to every nurse-patient encounter.

\subsection{Participants}

The study participants were recruited from an Ontario nursing school that incorporates simulation into its integrative nursing-education program. Given that this was a pilot study funded by the university's internal minor research grant, three undergraduate nursing students in their fourth year of study were recruited through a purposive sample. Each participant interacted with two SPs. Pseudonyms have been used to protect the anonymity of the participants (see Table 1).

Table 1. Demographics of participants

\begin{tabular}{lll}
\hline Case Study Participant & Gender & Age \\
\hline Participant 1 Diana & Female & 22 \\
Participant 2 Lorraine & Female & 25 \\
Participant 3 George & Male & 24 \\
\hline
\end{tabular}

\subsection{Data collection}

The study employed a qualitative exploratory and interpretive design. This approach guides the research process to explore the subjective experiences and construct themes illustrating the unique experiences of the student participants. The data was collected from each participant using (a) video recorded observation of individual interactions with SPs, (b) individual stimulated recall, and (c) individual participant interviews. Two SPs were utilized in the study, and each was trained to play the role of a patient within different clinical scenes. The interactions were videotaped and shown to participants, so they could reflect and comment on what they were thinking or doing during the simulation activity. Validity of the accounts and responses of the participants' interactions during the simulation activities are acknowledged as a limitation in this study. At the beginning of each simulation scenario, the video recording began once the participants had entered the room. Case-study methodology was employed to derive an up-close and in-depth understanding of the participants' experiences with SP methodology as a teaching-learning tool in their transition to practice.

\subsection{Ethical considerations}

After receiving institutional review board approval participants who signed informed consent forms were permitted to participate in the study. Participants were explained the purpose and process of the study and that they could withdraw from the study at any time. Participants were assured that the data collected in the study would be used entirely for the purpose of research and would not in any way affect their grades or performance in the program.

\subsection{Data analysis}

The study used thematic content analysis ${ }^{[16]}$ to derive themes from subthemes, which were drawn from the content of the transcripts. The interview transcripts were analyzed line by line to search for meaning, and the data was analyzed according to the traditional framework for qualitative data analysis. Data analysis involved a detailed case study write-up for 
each participant, which categorized interview questions and answers and examined the data for within-group similarities and differences. The data was organized and analyzed, case by case, for each participant simulation video recording, stimulated-recall session, and interview. The data was analyzed by data source, and the data analysis of the videotapes was based on observations of the participants' responses to SPs. The audiotapes of the stimulated-recall sessions and interviews were transcribed verbatim. Independent data analysis was then performed by: (a) reading and reviewing the data, (b) extracting significant statements, (c) formulating meanings, (d) organiznig aggregated meanings into themes, (e) integrating study findings, (f) formulating the description of investigated phenomena, and $(\mathrm{g})$ validating findings.

Essentially, the data-analysis process involved (a) immersion in each set of stimulated-recall interviews and in the video recordings (i.e., data was read and reflected upon until an overall understanding was achieved); (b) identification of significant statements and emerging meanings and themes; and (c) arrival at coherent and consistent interpretations. In order to gain a better understanding of the data collected, the data from the stimulated-recall sessions and the interviews were integrated. The research process including the data analysis were reviewed by one faculty member and a research assistant who have experience in qualitative research methods.

\section{RESUlts}

Four themes were derived from the thematic content analysis of the students' experiences regarding their interactions with the SPs and the learning that occurred as a result of these interactions: (1) embedding SP methodology in the curriculum as an experiential-education tool in the first year of the program, (2) practicing an emotional connection, (3) experiencing the reality of person-centred care, and (4) benefitting from improvisation in the context of standardized-patient methodology. These themes were further refined into nine associated subthemes. These subthemes are summarized in Table 2 and expanded upon in this section.

Table 2. Experiences of forth-year undergraduate nursing students with standardized patient methodology

\begin{tabular}{|c|c|}
\hline Themes & Subthemes \\
\hline $\begin{array}{l}\text { Theme 1. Embedding SP methodology in the } \\
\text { curriculum as an EE tool from first year of the } \\
\text { program }\end{array}$ & $\begin{array}{l}\text { - } \quad \text { Developing an understanding of the cultural aspect of nursing care } \\
\text { - } \\
\text { - } \\
\text { Developing mindfulness early on in the curriculum } \\
\text { including classrooms and clinical placement }\end{array}$ \\
\hline Theme 2. Practicing an emotional connection & $\begin{array}{l}\text { - Developing emotional intelligence } \\
\text { - } \quad \text { Embedding forms of affective domain in the curriculum }\end{array}$ \\
\hline $\begin{array}{l}\text { Theme 3. Experiencing the reality of } \\
\text { person-centred care }\end{array}$ & $\begin{array}{l}\text { - } \quad \text { Reinforcing the humanistic approach in the classroom } \\
\text { - } \quad \text { Lending empathy }\end{array}$ \\
\hline $\begin{array}{l}\text { Theme } 4 \text {. Benefitting from improvisation in the } \\
\text { context of standardized patient methodology }\end{array}$ & $\begin{array}{ll}\text { - } & \text { Refining communication skills } \\
\text { - } & \text { Interacting with a real person }\end{array}$ \\
\hline
\end{tabular}

\subsection{Developing an understanding of the cultural aspect of nursing care}

Participants commented on how the SP methodology allowed them to better understand the cultural aspect of nursing. The importance of this subtheme lies in its potential to impact a variety of aspects of health and patient outcomes and in the need to effectively embed it into curriculum. As one participant summarized,

"with a manikin you cannot see the emotion or the tone of voice of someone. You can't be given that in a practice session; it's very biomedical. Where this [SP methodology] reaches all aspects of health. For this situation we touched on aspects of her spirituality, you know, we touched on her emotional health, her mental health, her financial health, her family, her social support... where with a manikin, you can't do that. So I think that this would help a lot with practice before going into the clinical setting." [Diana]

\subsection{Developing mindfulness early on in the curriculum}

Participants commented that interactions with the two SPs provided them with an awareness of the need to develop a mindful approach to care. Further, they noted that feedback provided by the SPs helped them to develop this mindful approach and underscored the importance of embedding SP methodology early in the curriculum:

A patient isn't going to honestly say, you could have done this better, this is what you did right, that kind of thing... With the SP, it felt very real. 
I enjoyed her criticism and her telling me what I did right, what I did wrong, it felt good. It felt like I'm going to really take this [SP methodology] out and think about it and apply the corrections to a similar situation. [Lorraine]

This participant went on to note that the interaction allowed her to refine her approach and become more mindful and conscious of how she communicates both verbally and non verbally.

I was mindful of my messages, the way I was speaking, my tone, eye contact, body language. I placed my hand on the patient's back to reassure her and for a moment I had a discussion [with myself], I went back and forth on should I provide more, should I hold her hand, give her a hug at least or something like that. [Lorraine]

\subsection{Being exposed to SP methodology in a variety of con- texts}

The participants unanimously agreed that there is a need for this form of methodology to be integrated into the curriculum in a variety of contexts- "including clinical and theoretical"-from the classroom to the clinical practicum setting. They also noted the importance of early and continued integration of SP methodology, with Lorraine observing, "I think from year one to year four. I think it should be happening as soon you go to placement, like before you went to the clinical setting."

\subsection{Developing emotional intelligence}

Participants articulated that the application of SP methodology allowed them to develop and practice an emotional connection, with Diana stating that "the experience allowed [for] just being emotionally present." Diana also echoed the group's consensus that SP methodology is more effective than other forms of simulation in this regard: "In simulation [high technology], you can't practice an emotional connection at all, you know, you can't practice that therapeutic relationship." George summarized the impact of the methodology on the development of emotional intelligence:

It helped a lot and I think that, I find for me personally, that this all comes naturally, but I know for a lot of people it doesn't. So I think that if we were practicing this kind of stuff from day one, it could be a lot different. Like you can't practice an emotional connection or a therapeutic relationship or how to do open-ended questions, or anything like that. You can't practice that on a manikin, and for here [stimulated recall] I was able to and that was really neat, really you don't have the chance to watch yourself and critique yourself after a situation.

\subsection{Embedding forms of affective domain in the curricu- lum}

The study highlighted the need to embed methodologies that address the affective domain in the curriculum. As George observed, "[the affective domain] is a big hole in my care... This should be more of an imperative to work on in the future." Lorraine reinforced this observation, noting shortcomings in other forms of simulation:

In simulation with one-on-one patient care, we hadn't [addressed the affective domain]. We had no discussions of this nature. However, in our lab simulations all we did was clinical aspects. We were speaking with inanimate dummies and there is no back and forth, there is no discussion. There is no "How was your day, how are you doing?" It's just make sure you don't spill this IV or get yourself in trouble. There's no feedback. There's no emotional, the affective domain is missing.

George also discussed the positive impact that exposure to the affective domain had on his learning:

I think it was fantastic. It was very beneficial. I did not expect-I was not expecting to get so involved with it [interaction with SPs]. But I got emotional... you know, the feedback from the actresses was very comforting and reassuring... You can tell us how to behave and how to react and how to comfort a patient but never in practice, never in practice.

\subsection{Reinforcing the humanistic approach in the class- room}

The realistic nature of this form of simulation methodology reinforces the humanistic aspect of nursing and is aligned with the theoretical component of client-centered care. Lorraine noted, "It brings humanity to our care. We are not seen as simply robots. We are people as well. We go through these things with our patients. I think that reflects on the outcome."

The SP simulation exposed participants to interactions that provided them an opportunity to experience the meaningfulness of patient-centred care, thus reinforcing mindful practice and providing a lens to a holistic approach to nursing practice. Diana discussed the value of interacting with the whole patient and not just his or her symptoms.

ISSN 1925-4040 E-ISSN 1925-4059 
I think we should have more experiences like this in our curriculum. I think it is not realistic for us to expect to encounter certain experiences . . like I have never been on a maternity ward, I have never had to speak to a patient that was having a panic attack or needed me, not in terms of “okay, okay, I'll get your medication.” I never mentioned in the simulation, "Okay, I think you need some Tylenol." So I think we need more of this.

\subsection{Lending empathy}

Embedding empathy as a component of nursing practice is significant to developing emotional intelligence. Participants' experience with the notion of empathy was a critical finding in this study, as underscored by Diana: "I think that being involved in this form of learning has led me to better understanding that empathy is central to my care."

Interacting with the SP provided the participants with a deeper perspective of the meaning of empathy in the context of nursing practice and the importance of developing empathy in transition to practice. The emotions of the SP in the scenario led Lorraine to realize the significance of the realism this methodology provides and the impact it has had on her as person and as a nurse. The authentic component of interacting and sharing another's experience allowed Lorraine to feel the moment, be true to her feelings, and be more empathetic: "She had real tears. There was actual tears coming down her eyes. When she was upset I felt it. I felt that emotion. I felt that rawness. It just felt very real."

\subsection{Refining communication skills}

Interactions with the SPs allowed participants to reflect critically on their ability to communicate with patients. George noted, "I've come to realize that I'm not the expert I think I am and when put in a pressure situation I lose focus on clear and concise speaking." All participants acknowledged the value of SP methodology in refining their communication skills, as evidenced by Diana's comment:

Well now I'm very conscious about how the caring for people in the personal sense not just a clinical sense... while interacting with patients I can also now acknowledge how I speak to them, how they're responding, what kind of feedback they are giving. I think just overall consciousness on how-what kind of care I provide.

\subsection{Interacting with a real person}

Participants were enthusiastic about the experience. After being exposed to the second SP scenario, Lorraine noted,
"That was awesome, that was terrific. I swear to God, I thought it was real. I completely forgot there was a camera and everything." She elaborated on the process:

I feel like each time it happens, it will improve. This time I don't think I looked at the camera once, I completely forgot it was there and when the timer went off I was actually upset, I wanted to keep going. I was like, 'I'm not finished with her yet", like I want to help her more. Where before I was like, "Is this timer going to go off yet? I don't know what to say. I feel uncomfortable." With here [second scenario] I didn't feel that way, I felt very on point.

Diana also discussed the essential contribution the actors made in creating realistic scenarios:

It seemed very natural, you know. Right when I walked in, she was cursing, she kind of threw her cigarettes down... it felt real, it didn't feel forced. Like when she was crying, there was real tears and I was right by her side. I was like, oh my goodness, it just felt, I think it's because she was actually crying that it just felt so real, just emotions on her face.

\section{Discussion}

It is well documented that the use of simulation-based methodology provides an active learning environment; debriefing and self-reflection further enhance knowledge and skill development of both teachers and learners. ${ }^{[7,17]}$ As indicated in this study, SP methodology affords several advantages; it allows for repeatability; supports the development of communication and interviewing skills; and provides the learner with feedback on professional mannerism, attitude, and interpersonal skills. Moreover, this feedback is immediate and from the patient's point of view. SP encounters are also beneficial to the development of professional competence, communication skills, and confidence in practice, as they provide students an opportunity to develop competency in difficult interpersonal situations - such as dealing with angry clients or workplace conflicts, relaying bad news, or asking personal questions of clients - in a safe and supervised environment without compromising workplace safety. ${ }^{[18,19]}$ However, poorly planned, organized, and executed simulations can result in student frustration and failure of the exercise to meet the learning objectives. ${ }^{[2]}$

This study reinforces earlier research on the uses of SP methodology. The findings support that this approach enhances learner's clinical and critical thinking skills ${ }^{[20,21]}$ including self-assessment, emotional intelligence, and empa- 
thetic skills. ${ }^{[20]}$ In keeping with earlier studies, the participants were able to illustrate problem-solving and decisionmaking skills ${ }^{[22]}$ by illustrating patient-centred attitude and health teaching ${ }^{[20,23]}$ through communication and collaboration skills. ${ }^{[24]}$

The study identifies that the educational use of SP methodology is valuable in the nursing curriculum, as SPs can consistently present the same problems to any student, at any time needed for learning, and in any arena, including a classroom or non-clinical environment. Further, learning can take place in a safe environment that effectively and realistically simulates clinical settings, yet does not involve real patients or require dealing with the complexities of ethics and regulations at hospitals.

When applied in an educational environment, simulation provides the educator an opportunity to create and control a learning milieu by introducing realistic scenarios to meet learning objectives; this affords an opportunity for feedback and enhances integration of theory and practice through processes of debriefing and guided reflection. ${ }^{[25-27]}$ Yet this approach remains underutilized in undergraduate programs across a variety of disciplines. ${ }^{[27]}$ From this study, I posit that increasing and expanding the use of this form of experiential education into other disciplines can provide rich learning experiences to a greater number of students. A wider focus on humanities and social-sciences disciplines-such as social work, education (including early childhood education) and law, to name a few-would make for a unique initiative within the academic community, though further research would first be required into how educators can effectively apply and embed SP methodology across a variety of disciplines. ${ }^{[28]}$ Exploring the efficacy of the SP-methodology tool in teacher education and its value as a teaching-learning approach catering to professional disciplines is imperative to enhance student engagement and knowledge retention.

In addition to expanding the use of SP methodology into other disciplines, this study's findings highlight a need to implement it over the duration of nursing programs. Successful implementation, however, requires that faculty be knowledgeable about how to apply this methodology and how to work with SPs. While the need to successfully train teachers in the method is apparent, there is a lack of scholarship on how to accomplish this. Thus, the possible benefit and effectiveness of the use of SPs on faculty development is unknown. Nonetheless, a few studies have great potential to enhance teaching skills and curricula/educational program design. ${ }^{[29]}$

Olive et al. ${ }^{[30]}$ outline a process for developing SP cases. Other studies explore the effects of teaching methods using
SPs, ${ }^{[22]}$ report on how to integrate SP in the course curriculum, ${ }^{[31]}$ and review standards of practice in SP case-materials development, recruitment, training, and quality assurance.

While the findings from this study support integrating SP methodology beginning with the first year of study, more research is needed to determine how this knowledge is to be translated into practice ${ }^{[21,32]}$ and confirm the effectiveness of SPs on the learner performance. ${ }^{[33]}$ A review of the literature on the use of SPs, ${ }^{[21]}$ confirms that SP methodology is frequently used in teaching, learning, and evaluating learners' competency. Although the majority of studies reported changes in knowledge, skills, or attitudes of the learners, little research has been done to evaluate SP use in teaching and learning, (e.g., behavioural changes in the learners, which are a key indicator of the change in the delivery of patient care and may have a notable impact on patient outcomes). ${ }^{[34]}$ Such changes have been observed by Nestel and Bearman, ${ }^{[4]}$ who note that SP methodology has affective or emotional dimensions that learning theories should consider.

Finally, changing requirements of the Canadian nursing registration exam may impact the popularity of SPs in Canadian contexts. According to May et al., ${ }^{[21]}$ SP methodology's popularity in medical education in the United States is a result of the US Medical Licensure Examination (USMLE). The adoption of the NCLEX-RN as the Canadian nursing registration exam will likely have a similar effect on learning needs and quality of education in Canada. Given these new standards and requirements, it is imperative that Canadian institutions adopt effective training methodologies, such as SP, to support student success. As most of the scholarship regarding the use of SP methodology is in the field of medical education, the results of these many studies can be used to design or modify nursing programs. Doing so has the potential to enhance a broad range of skills, such as assessment, communication, history taking, examination, cultural competence, problem-solving, decision-making, reflection, collaboration, leadership, teamwork, and core nursing skills.

\section{RECOMMENDATIONS}

Although this research study offers some interesting findings in the field of SP methodology in nursing education, particularly in the area of students' experiences with the methodology, more research is needed. The findings of this research study have also provided insight into the significance of the link between theory and practice in nursing education; to explore this link, nursing curriculum would need to make a clear association between the essential elements of nursing theories and practice, and provide sufficient practice-based learning experiences by developing SP scenarios relevant to both nursing education and requirements of the NCLEX. 
Further research is needed to augment the findings from this research. Other scholars might consider the following research options:

(1) Address the need for more well-designed research with a strong theoretical framework in order to provide reliable evidence of SP use and efficacy on learner practice, learner behaviours, and patient outcomes.

(2) Implement larger scale studies similar to the one under discussion.

(3) Conduct further research into how educators can best develop effective skills for training and coaching students using SP methodology across various disciplines, including teacher education, social work, and law.

(4) Further investigate the teachers or teaching skills needed to successfully utilize SP methodology in the context of professional development.

(5) Explore the application of SP methodology into other disciplines including teacher education social work and law.

\section{Conclusion}

This research can act as a foundational piece of knowledge development in the area of undergraduate education of professionals. Despite the limitations mentioned above, the value of the methodology cannot be ignored.

In this research, response to SP methodology was, overall, positive; participants agreed that the experiences were realistic, the SP's feedback was beneficial, and the challenge level was appropriate. Participants also noted both an imperative need to embed the affective domain in the curriculum, and the ability of SP methodology to address this need. The self-reported benefits noted by participants include gains in knowledge of person-centered care and mindfulness; when multiple SP interactions were available, participants expressed decreased anxiety and increased familiarity and comfort with this teaching-learning environment. In situations where participants provided negative feedback, re- sponses were linked to the need for enhancing either realism or the quality of the improvisation provided by the SP, which emphasizes the need to explore this notion further.

Yet, despite these promising findings, limited research has been conducted on the application of SP methodology and how educators embed or utilize it in their teaching, on its impact on student learning, or on its success in developing the professional competence of learners transitioning into the workplace. ${ }^{[25,35-39]}$ Further, limited knowledge exists on the interaction between educators and SPs in the context of teaching-learning milieus; the effectiveness of SP encounters as a teaching methodology in professional undergraduate programs; and the application of SPs for educational purposes within professional disciplines other than medicine, such as nursing, law, business, social work, and education. ${ }^{[40-42]}$ There is a similar dearth of scholarship into the use of SPs in current nursing programs in Canada. Given the limited number of studies in this area, there is no clear tradition of utilizing this form of methodology in learning and teaching, especially for faculty professional development.

These gaps in the research must be addressed. Given the positive results of this study, further research into, and implementation of, SP-methodology integration in nursing programs is recommended. The value of this methodology is perhaps best summed up by one of the study's participants. As George states,

I think my life in nursing could have been a lot better, if we did this from day one to be quite honest. I really liked the feedback [from the SP] as well. You can't get that with real life patients.

\section{ACKNOWLEDGeMENTS}

This research was supported by a York University Faculty of Health Minor Research Grant.

\section{CONFlicts of InTERest Disclosure}

The authors declare that there is no conflict of interest.

\section{REFERENCES}

[1] Wilson L, Rockstraw L. Human simulation for nursing and health professions. New York: Springer; 2012. 392 p.

[2] Howden E. Outdoor experiential education: Learning through the body. New Dir Adult Contin Educ. 2012 Jun; 134: 43-51. http: //dx.doi.org/10.1002/ace.20015

[3] Sherwood G, Horton-Deutsch S, editors. Reflective practice: Transforming education and improving outcomes. Indianapolis: Sigma Theta Tau Press; 2012. 345 p.

[4] Nestel D, Bearman M. Simulated patient methodology: Theory, evidence and practice. Hoboken: Wiley-Blackwell; 2014. 168 p http://dx.doi.org/10.1002/9781118760673

[5] Festa LM, Baliko B, Mangiafico T, et al. Maximizing learning outcomes by videotaping nursing students' interactions with standardized a patient. J Psychosoc Nurs. 2000 May; 38(5): 37-44.

[6] Epstein R, Hundert E. Defining and assessing professional competence. J Amer Med Assoc. 2002 Jan; 287(2): 226-35. PMid:11779266 http://dx.doi.org/10.1001/jama.287.2.226

[7] Jeffries PR, editor. Simulation in nursing education from conceptualization to evaluation. 2nd ed. New York: National League for 
Nursing; 2012. 288 p.

[8] National Council of State Boards of Nursing. Clinical instruction in prelicensure nursing programs [Internet]. 2005 [cited 2016 May 3]. Available from: https://www.ncsbn.org/Final_Clinical _Instr_Pre_Nsg_programs.pdf

[9] Henneman EA, Cunningham H, Roche JP, et al. Human patient simulation: Teaching students to provide safe care. Nurs Educ. $2007 \mathrm{Sep}$; 32(5): 212-7. PMid:17828022 http://dx.doi.org/10.1097/0 1.NNE.0000289379.83512.f C

[10] Anderson M, Holmes TL, LeFlore JL, et al. Standardized patients in educating student nurses: one school's experience. Clin Simul Nurs 2010 Mar; 6: e61-6. http://dx.doi.org/10.1016/j.ecns . 20 09.08 .001

[11] Vessey JA, Huss K. Using standardized patients in advanced practice nursing education. J Prof Nurs. 2002 Jan; 18(1): 29 35. PMid:11859491 http://dx.doi.org/10.1053/jpnu. 2002 .30898

[12] Peisachovich EH. The experience and understanding of clinical judgment of internationally educated nurses. J Nurs Educ Pract. 2015 Aug; 5(8): 33-43. http://dx.doi.org/10.5430/jnep.v5n8p33

[13] Peisachovich EH. The importance of intercultural fluency in developing clinical judgment. J Nurs Healthc. 2015 Sep; 2(2): 53-9.

[14] Oh PO, Jeon KD, Koh MS. The effects of simulation-based learning using standardized patients in nursing students: A meta-analysis. Nurs Educ Today. 2015 May; 35(5): 6-15. PMid:25680831 http: //dx.doi.org/10.1016/j.nedt.2015.01.019

[15] Rodehorst TK, Wilhelm SL, Jensen L. Use of interdisciplinary simulation to understand perceptions of team members roles. J Prof Nurs. 2015 May; 21(3): 159-66. http://dx.doi.org/10.1016/j.pro fnurs.2005.04.005

[16] Anderson R. Thematic content analysis (TCA): Descriptive presentation of qualitative data using Microsoft Word. (Unpublished manuscript). 2007

[17] Peisachovich EH. Succeeding on the Canadian NCLEX-RN: Incorporating experiential learning approaches in the education of internationally educated nurses. J Nurs Educ Pract. 2016 Mar; 6(7): 101-8. http://dx.doi.org/10.5430/jnep.v6n7p101

[18] Galloway SJ. Simulation techniques to bridge the gap between novice and competent healthcare professionals. Online J Issues Nurs [Internet]. 2009 [cited 2016 May 3]; 14(2): Manuscript 3. Available from: http://www.nursingworld.org/MainMenuCategorie s/ANAMarketplace/ANAPeriodicals/OJIN/TableofConten ts/Vol142009/No2May09/Simulation-Techniques.html

[19] Lane C, Rollnick S. The use of simulated patients and role-play in communication skills training: A review of the literature. Patient Educ and Couns. 2007 Jul; 67(1-2): 13-20. PMid:17493780 http://dx.doi.org/10.1016/j.pec.2007.02.011

[20] Herge EA, Lorch A, Deangelis T, et al. The standardized patient encounter: A dynamic educational approach to enhance students' clinical healthcare skills. J Allied Health. 2013 Winter; 42(4): 22935. PMid:24326920

[21] May W, Park JH, Lee JP. A ten-year review of the literature on the use of standardized patients in teaching and learning: 19962005. Med Teach. 2009 Jun; 31(6): 487-92. PMid:19811163 http: //dx.doi.org/10.1080/01421590802530898

[22] Fey MK, Scrandis D, Daniels A, et al. Learning through debriefing: Students' perspectives. Clin Simul Nurs. 2014 May; 10(5): e249-56. http://dx.doi.org/10.1016/j.ecns.2013.12.009

[23] Nehring W, Lashley F. Nursing simulation: A review of the past 40 years. Simul Gaming. 2009 Aug; 40(4): 528-52. http://dx.doi.o $\mathrm{rg} / 10.1177 / 1046878109332282$
[24] Kameg K, Howard VM, Clochesy J, et al. The impact of high fidelity human simulation on self-efficacy of communication skills. Issues Ment Health Nurs. 2010 May; 31(5): 315-23. PMid:20394477 http://dx.doi.org/10.3109/01612840903420331

[25] McGaghie WC, Issenberg B, Petrusa ER, et al. A critical review of simulation based medical education research 2003-2009. Med Educ. 2010 Jan; 44(1): 50-63. PMid:20078756 http://dx.doi .org/10. $1111 / \mathrm{j} .1365-2923.2009 .03547 . \mathrm{x}$

[26] Peisachovich EH. Reflection beyond action: A modified version of the "reflecting" phase of Tanner's Clinical Judgment Model. Int J Nurs Health Sci. 2016 Mar; 3(2): 8-14.

[27] Medley CF, Horne C. Using simulation technology for undergraduate nursing education. J Nurs Educ. 2005 Jan; 44(1): 31-4. PMid: 15673172

[28] Salas E, Wildman JL, Piccolo RF. Using simulation-based training to enhance management education. Acad Manag Learn Educ. 2009 Dec; 8(4): 559-73. http://dx.doi.org/10.5465/AMLE. 2009 .47785474

[29] Broad K, Evans M. A review of literature on professional development content and delivery modes for experienced teachers [Internet]. Initial Teacher Education Program; c2006 [cited 2016 May 1]. Available from: https://www.oise.utoronto.ca/ite/UserFiles /File/AReviewofLiteratureonPD.pdf

[30] Olive EK, Elnicki DM, Kelley MJ. A practical approach to developing cases for standardized patients. Adv Health Sci Educ Theory Pract. 1997; 2(1): 49-60. PMid:16180058 http://dx.doi.org/1 $0.1023 / \mathrm{A}: 1009704030279$

[31] Rethans JJ, Grosfeld FJM, Aper L, et al. Six formats in simulated and standardized patients use, based on experiences of 13 undergraduate medical curricula in Belgium and the Netherlands. Med Teach. 2012; 34(9): 710-6. PMid:22905657http://dx.doi .org/10. 31 09/0142159X . 2012.708466

[32] Owen AM, Ward-Smith P. Collaborative learning in nursing simulation: Near-peer teaching using standardized patients. J Nurs Educ. 2014 Mar; 53(3): 170-3. PMid:24530131 http://dx.doi.org/1 $0.3928 / 01484834-20140219-04$

[33] Li S, Kenward K. A national survey of nursing education and practice of newly licensed nurses. JONAS Healthc Law Ethics Regul. 2006 Oct; 8(4): 110-5. PMid:17149038 http://dx.doi.org/10.1097 /00128488-200610000-00004

[34] Wear D, Varley JD. Rituals of verification: The role of simulation in developing and evaluating empathic communication. Patient Educ Couns. 2008 May; 71(2): 153-6. PMid:18282681 http: //dx.doi.org/10.1016/j.pec.2008.01.005

[35] Bordt RL. Simulation as a tool for teaching research methods in a criminology course. J Crim Just Educ. 1999 Oct; 10(2): 373-82. http://dx.doi.org/10.1080/10511259900084681

[36] Robertson HJ, Paige JT, Bok L. Simulation in radiology. Oxford: Oxford University Press; 2012. 336 p. http://dx.doi.org/10. $1093 / \mathrm{med} / 9780199764624.001 .0001$

[37] Stanyon W, Goodman B, Whitehouse M. Using simulation to educate police about mental illness: A collaborative initiative. Gateways. 2014; 7(1): 52-66. http://dx.doi.org/10.5130/ijcre.v7i1. 3394

[38] Tashiro J, Dunlap D. The impact of realism on learning engagement in educational games. Proceedings of the 2007 Conference on Future Play. New York: ACM; 2007 Nov. 113-20 p. http: //dx.doi.org/10.1145/1328202.1328223

[39] Hardee JT, Kasper IK. From standardized patient to care actor: Evolution of a teaching methodology. Perm J. 2005 Summer; 9(3): 79-82. PMid:22811638 http://dx.doi.org/10.7812/TPP/05-030 
[40] Curran VR. Interprofessional education and patient safety competencies [Internet]. The Task Force on Adverse Health Events; 2008 [cited 2016 May 4]. Available from: http://www.gov.nl.ca/ahe/su bmissions/07_CentreforCollaborativeHealthProfessio nalEducation \T1\textemdashMemorialUniversity.pdf

[41] Polit DF, Beck CT. Nursing research: Generating and assessing evi- dence for nursing practice. 9th ed. Philadelphia: Lippincott, Williams, \& Wilkins; 2012. 768 p.

[42] Dzioba J, Cant R, Cooper S, et al. Barriers and enablers to learning during team-based clinical simulations: Reflective interviews with final year undergraduate nursing students. J Nurs Educ Pract. 2014; 4(10): 32-9. http://dx.doi.org/10.5430/jnep.v4n10p32 